\title{
Development and characterization of transparent and conductive InZnO films by magnetron sputtering at room temperature
}

J. Nicholas Alexander ${ }^{1}$, Neville Sun ${ }^{2}$, Richard Sun ${ }^{2}$, Harry Efstathiadis ${ }^{1}$, and Pradeep

\section{Haldar $^{1}$}

${ }^{1}$ State University of New York Polytechnic Institute, Colleges of Nanoscale Science and Engineering, 257 Fuller Rd., Albany, NY 12203, USA

${ }^{2}$ Angstrom Sun Technologies Inc., 31 Nagog Park, Acton, MA 01720, USA

\begin{abstract}
The electrical and optical properties of InZnO for use as a transparent conducting oxide (TCO) is reported through the investigation of the concentration of indium and oxygen in the film. InZnO films (10-30 wt\% In) were deposited by magnetron sputtering without substrate heating or annealing from a ceramic $\mathrm{ZnO}$ and a metallic indium target The film's properties were investigated by X-ray photoelectric spectroscopy (XPS), 4point probe, UV-vis spectroscopy (UV-VIS), spectroscopic ellipsometry, and Hall measurements. InZnO films obtained properties with low resistivity, on the order of $\sim 5.5 \times 10^{-4} \mathrm{ohm}-\mathrm{cm}$, with a mobility $\sim 35 \mathrm{~cm}^{2} / \mathrm{V} \cdot \mathrm{S}$, and carrier concentrations $\sim 3^{*} 10^{20} \mathrm{~cm}^{-3}$. The band-gap ranged from $2.7-3.2 \mathrm{eV}$ with transmission of several samples $>80 \%$. InZnO has demonstrated properties adequate for photovoltaic applications.
\end{abstract}

Keywords: Oxide Materials, Semiconductors, Thin Films, Electronic Properties, Optical Properties 
Corresponding Author Email: JAlexander@albany.edu

Tel: 518-406-6124

Postal: SUNY Polytechnic Institute,

Colleges of Nanoscale Science and Engineering

251 Fuller Rd., Albany NY 122 


\section{Introduction}

Transparent conducting oxide (TCO) films have gained significant importance, due to their low film resistivity and their high transparency. These physical properties have led to the use of TCOs in applications such as flat panel displays, which consist most notably of liquid crystal displays (LCD) and organic light emitting diodes (OLED), and in thin film solar cell applications such as amorphous $\mathrm{Si}, \mathrm{CuInGaSe} 2$ (CIGS), CdTe, and CuZnSbSe [1-3].

Traditionally, many thin-film solar cells, in particular CIGS, use indium tin oxide (ITO), which is the most commonly used TCO for devices [4]. In recent years, due to unstable pricing and a relatively small indium supply, new materials have been sought to either reduce or remove indium use [5,6]. Studies were performed on new materials systems, such as $\mathrm{ZnO}$ doped with trivalent dopants such as boron, aluminum, gallium, and indium. The best results obtained to date with trivalent doped $\mathrm{ZnO}$ are with aluminum. Aluminum doped zinc oxide has been used as a TCO for CIGS in past record efficiency achieving devices, and also in past studies [7,8]. Most $\mathrm{ZnO}$ doped films suffer from transmission loss with high carrier concentrations, particularly in the near-infrared, in relation to similar carrier concentrations of other materials systems, such as ITO and IZO [9]. Research into the $\mathrm{ZnO}$ material system is heavily on going due to the attractive low cost of $\mathrm{ZnO}$. Co-doping of the $\mathrm{ZnO}$ to enhance the electrical and optical properties of the films has been an active area for new material development [10,11]. Indium zinc oxide was also investigated as a replacement for ITO and has shown improved performance on a completed CIGS device, however the amount of indium in this film is comparable to that of ITO [12]. 
A less investigated region in the $\mathrm{ZnO}-\mathrm{In}_{2} \mathrm{O}_{3}$ material system that was explored in this research is the case when the $\mathrm{Zn} /(\mathrm{Zn}+\mathrm{In})$ ratio is greater than 0.5 and less than 0.9 , which consists of the $\mathrm{Zn}_{\mathrm{x}} \mathrm{In}_{2} \mathrm{O}_{\mathrm{x}+3}$ type structure, which contains less indium than traditional ITO. In a previous report, InZnO deposited by pulsed laser deposition (PLD) from a $\mathrm{ZnO}$ and $\mathrm{In}_{2} \mathrm{O}_{3}$ target materials, good electrical measurements in this region were reported, and a decrease in carrier concentration was found until a $\mathrm{Zn} /(\mathrm{Zn}+\mathrm{In})$ ratio of about 0.8 , which could increase optical transmittance, especially in the near infrared [13]. These concentrations of indium in the film may allow for enhanced mobility without increasing carrier concentration to yield films with better transmission and electrical results. The same group that deposited the films with PLD reported improved transmission with the $\mathrm{Zn}_{2} \mathrm{In}_{2} \mathrm{O}_{5}$ phase, although they did not provide any data. In another study in an effort to reduce the indium content in TCOs, deposited films of indium zinc tin oxide. which had physical properties comparable to ITO but using significantly less indium [6]

In this work, the properties of $\mathrm{InZnO}$ as deposited by magnetron sputtering with a $\mathrm{Zn} /(\mathrm{Zn}+\mathrm{In})$ ratio between 0.5 and 0.9 are investigated. The power of the indium target and the fraction of oxygen in argon gas (referred to as the oxygen volume fraction) were varied to deposit films with high conductivity and transparency at room temperature with different $\mathrm{Zn} /(\mathrm{Zn}+\mathrm{In})$ ratios. The goal of this work is to deposit InZnO films with less indium than traditional ITO with good electrical and optical properties at room temperature and no post deposition anneal. The results of such will be discussed in this paper.

\section{Experimental}




\subsection{Precursor deposition}

All InZnO films in this study were deposited in an AJA International Inc. ATC physical vapor deposition reactor equipped with three, 3 " diameter confocal magnetron sputtering guns and a load lock. The targets were a ceramic i-ZnO and a pure indium (99.999\% purity) disks purchased from Plasmaterials Inc. The guns were positioned in a confocal alignment, allowing for simultaneous deposition of the precursor elements, and were driven independently by a $13.56 \mathrm{MHz}$ rf and a DC power supply. The deposition tool was also equipped with rotating wafer stage for maintaining film thickness and a uniform composition. The reactor was evacuated using a combination of a mechanical pump and turbomolecular pump to a base pressure of $\sim 5 \times 10^{-7}$ Torr.

The InZnO films were deposited on 1"x3" soda-lime glass (SLG) and 1'x1' of polished boron doped p-type $\mathrm{Si}(100)$ substrates with a resistivity greater than $1 \mathrm{ohm}-\mathrm{cm}$. No special treatment was performed on the substrates before deposition except to blow them off with dry nitrogen prior to loading them in the load lock.

Before each deposition, the targets were cleaned by sputtering with the gun shutters closed to remove any excess oxides or contaminants that may have accumulated, and then run simultaneously to co-sputter at varying indium power to deposit $\mathrm{InZnO}$ with varying stoichiometry. The deposition power for the $\mathrm{ZnO}$ target was kept at $120 \mathrm{~W}$, while the indium power was 20,40 , and $60 \mathrm{~W}$, respectively. All the $\mathrm{InZnO}$ films were grown at room temperature. All other deposition parameters, such as process pressure and total gas flow rate, remained constant at $2 \mathrm{mT}$ and $10 \mathrm{sccm}$ (unless noted with an *, which indicates a flow rate other than 10), respectively. The gas flow mixture was varied by 
mixing two gases, argon gas and a $4 \%$ oxygen/argon gas, while keeping a constant sum of the flow rates.

During this study, samples were stored in a nitrogen glove box with humidity control to limit possible effects by the ambient environment. Hall measurements were performed on $\sim 1 \mathrm{~cm}^{2}$ glass pieces with indium contacts soldered on the four corners.

\subsection{Film characterization}

Film microstructural, optical, and electrical properties were investigated by a number of analytical techniques. All sample characterization discussed was performed on the InZnO films deposited on soda-lime glass substrates, with the exception of X-ray photoelectron spectroscopy, which was performed on silicon substrates.

The film thickness and optical constants of the InZnO films were obtained by using a spectroscopic ellipsometer TFProbe, SE500BA, developed by Angstrom Sun Technologies Inc. The spectroscopic ellipsometry technique allows for non-contact and non-destructive measurements of relative phase change of reflected and polarized light on any section of the film. The physical and optical properties of the InZnO films were acquired by fitting the measured ellipsometry parameters, Psi $(\Psi)$ and Delta $(\Delta)$, to the model data using a theoretically calculated set of parameters. The parameter $\Psi$ is defined

by the following equation that includes the complex Fresnel reflection coefficients $\mathrm{R}^{\mathrm{P}}$ and $\mathrm{R}^{\mathrm{S}}$, representing the reflected parallel component $(\mathrm{P})$ and the perpendicular component (S) relative to the incident plane, respectively. Parameter $\Delta$ is the phase difference induced by the reflection and is obtained by analyzing the film stack and substrate in the system. 


$$
\rho=\frac{R^{P}}{R^{S}}=\operatorname{Tan} \Psi \cdot \mathrm{e}^{j \Delta}
$$

The spectroscopic ellipsometry measurements were performed in the wavelength range from $250 \mathrm{~nm}$ to $1700 \mathrm{~nm}$. All samples were measured at $65^{\circ}, 70^{\circ}$, and $75^{\circ}$ incident angles with 512 wavelength points. Using the TFProbe 3.3 software, a Tauc-Lorentz dispersion model was applied on the measured data sets to obtain the optical functions of the InZnO films. The imaginary part of the dielectric function $\varepsilon_{\mathrm{i}}$ was developed by Jessison and Modine in 1996, by multiplying the Tauc joint density of states with the Lorentz oscillator:

$$
\begin{gathered}
\varepsilon_{i}(E)=\frac{A E_{0} C\left(E-E_{G}\right)^{2}}{\left(\left(E^{2}-E_{0}\right)^{2}+C^{2} E^{2}\right) E}, \quad E>E_{g}, \\
\varepsilon_{i}(E)=0, \quad E \leq E_{g}
\end{gathered}
$$

where $\mathrm{E}_{0}$ is the peak transition energy, $\mathrm{C}$ is the broadening term, $\mathrm{E}_{\mathrm{g}}$ is the optical band gap, and A is proportional to the transition probability matrix element $[14,15]$.

The real part of the dielectric function $\varepsilon_{\mathrm{r}}$ is calculated by Kramers-Kronig integration:

$$
\varepsilon_{r}(E)=E_{\text {inf }}+\frac{2 P}{\pi} \int_{E_{g}}^{\infty} \frac{\xi \varepsilon_{i}(\xi)}{\xi^{2}-E^{2}} d \xi
$$

The fitting parameters in the software utilizes the variables $A, C, E_{0}, E_{g}$ and $E_{\text {inf }}$ from the Tauc-Lorentz model.

When studying optical property over a very wide wavelength range, especially for TCO films, the Tauc-Lorentz dispersion is inadequate to describe the dielectric response completely. Therefore, one or more Lorentz type oscillators were added into the total dielectric function in the analysis [16]:

$$
\varepsilon_{r}=\frac{A_{1} \lambda^{2}\left(\lambda^{2}-L_{0}^{2}\right)}{\left(\lambda^{2}-L_{0}^{2}\right)^{2}+\gamma^{2} \lambda^{2}}
$$




$$
\varepsilon_{i}=\frac{A_{1} \lambda^{3} \gamma}{\left(\lambda^{2}-L_{0}^{2}\right)^{2}+\gamma^{2} \lambda^{2}}
$$

where $A_{1}$ is the amplitude, Lo is the central wavelength, and $\gamma$ is the width of the oscillators. These three parameters are variables to be fitted using regression.

The Levenberg - Marquardt algorithm (LMA), a non-linear least-Squares method, was used for modeling. The best fitted variables can be found by minimizing $\chi^{2}[17]$ :

$$
\chi^{2}=\frac{1}{2 n-m-1} \sum_{i=1}^{n}\left[\left(\operatorname{Tan} \Psi_{\text {Theory }}^{i}-\operatorname{Tan} \Psi_{E x p}^{i}\right)^{2}+\left(\operatorname{Cos} \Delta_{\text {Theory }}^{i}-\operatorname{Cos} \Delta_{E x p}^{i}\right)^{2}\right]
$$

where $\operatorname{Tan} \Psi_{\text {Theory }}$ and $\operatorname{Cos} \Delta_{\text {Theory }}$ are the modeled values, Tan $\Psi_{\text {Exp }}$ and $\operatorname{Cos} \Delta_{\text {Exp }}$ are measured values, $\mathrm{m}$ is the number of variables to be fitted, and $\mathrm{n}$ is the data points. The fitting process seeks to adjust those variables that could minimize the value $\chi^{2}$. Since more data points and fewer variables would make fitting results more reliable and with smaller uncertainty, variable incident angle data sets will produce higher quality ellipsometry analysis results in general.

Film thickness was also measured using an Alpha-step 200 profilometer for comparison. Composition measurements were performed with a Thermo Fisher ThetaProbe X-ray photoelectron spectroscopy (XPS). The spectrometer was equipped with a hemispherical analyzer and a monochromater and all XPS data was measured with Al ka X-rays (1486.6 eV) operated at $100 \mathrm{~W}$ and an analyzer at 45 degrees. Hall measurements of Van der Pauw geometry were performed to measure the mobility, carrier concentrations, and sheet resistance of the films.

\section{Results and discussion}

\subsection{Film composition and growth}


XPS depth profile was employed to determine film compositional characteristics. Approximately $100 \mathrm{~nm}$ of the top of the film were sputtered off using an ion gun inside the XPS chamber to perform the analysis without the presence of surface contamination.

In Fig. 1, the elemental concentrations of indium, zinc, and oxygen are shown for each indium deposition power for given concentrations of oxygen in $10 \mathrm{sccm}$ of argon/oxygen mixture. For these films, oxygen concentration is critical for the deposition of ideal TCO films, as will be seen from the physical properties. With no oxygen in the gas mixture, films will deposit as an opaque film with a silver color, and require oxygen to become transparent.

From the results in Fig. 1, it was observed that as the oxygen volume fraction is increased, the content of oxygen and indium in the film increased in the opaque region. This was probably due to the bonding of oxygen and metallic indium atoms which continues to have this effect until the film becomes a transparent oxide. As anticipated, the higher the indium target power or higher the indium content, the more oxygen was required to produce a transparent film.

Fig. 2 shows the growth rates with respect to the indium power and their respective oxygen volume fraction in the argon-oxygen gas mixture. As oxygen is being incorporated into the film to form a more transparent oxide, the film growth rates remained almost constant. Once the film became transparent, the increase of the oxygen volume fraction started to inhibit the growth of the film, particularly in the 20 and $40 \mathrm{~W}$ cases. It is currently unclear if $60 \mathrm{~W}$ indium would follow the same trend.

\subsection{Optical transmission}


For this section, transmission data were measured in the wavelength region from 250 $\mathrm{nm}$ to $1700 \mathrm{~nm}$. It was important to include data up to this wavelength to provide insight on the near-infrared region $(750-1400 \mathrm{~nm})$ and a small portion of the short-wavelength infrared (1400-3000 nm), as TCO films typically start to absorb in this range [9].

Fig. 3 displays the transmission spectra for InZnO films on SLG. For each indium target power, it was found that increasing the oxygen volume fraction increases the transmission. This also applies to the transparent films. The limit to the increase of the oxygen volume fraction, is that the resistivity of the films increases as the volume fraction increases. The transmission of the best performing samples were similar in the visible region were the samples $20 \mathrm{~W} 1.20 \%$ and $40 \mathrm{~W} 2.80 \%$, but the $60 \mathrm{~W} 4.00 \%$ sample is a little less transparent. It may be possible to enhance the transmission of the $60 \mathrm{~W}$ sample by increasing the oxygen partial pressure. The infrared transmission of the best performing samples varies, with the best performance from the $40 \mathrm{~W} 2.80$ indium sample, and the $20 \mathrm{~W} 1.20 \%$ and $60 \mathrm{~W} 4.00 \%$ samples similar to each other.

Fig. 4 shows the linear fits of the Tauc plots of the samples shown in Fig. 3. The films with poor transparent properties were not fit, as some of them exhibited properties closer to a metallic sample and are not useful for the application in mind. The band-gap varies in the transparent samples from about $2.7-3.0 \mathrm{eV}, 2.8-3.2 \mathrm{eV}$, and 3.0-3.2 eV, for the $20 \mathrm{~W}, 40 \mathrm{~W}$, and $60 \mathrm{~W}$ indium, respectively. Typically, the band-gap drops as the oxygen volume fraction is increased. The largest band-gap is seen in the samples that occur right after the transition to transparent samples; these samples typically do not have as good transmission along the spectrum. The conductive high transparent samples follow after those samples with a small drop in band-gap. The band-gap drops even 
farther as the samples transition farther into the less conductive region. The band-gap of all the optimized samples are similar, within the 3.0 to $3.1 \mathrm{eV}$ region.

The band-gap of the optimized films shows they are adequate for solar applications and have transmissions on par with other transparent conducting oxides that are used.

\subsection{Electrical measurements}

Film resistivity was measured by 4-point probe, and mobility and carrier concentration by Hall measurements were performed on square $\sim 1 \mathrm{~cm}^{2}$ pieces of InZnO/SLG, with four $<0.1 \mathrm{~cm}$ diameter indium solder balls on the sample corners.

Fig. 5 shows the sheet and bulk resistivity of the deposited films. The resistivity values of the non-transparent films were generally higher than their transparent counterparts. This is probably due to a more metallic structure of the non-transparent films. As the oxygen volume fraction was increased, the resistivity of the nontransparent samples was increased until they transitioned and became transparent. After becoming transparent, there is a decrease in resistivity. The samples now are transparent and conductive for a range of oxygen partial pressures until resistivity starts to increase significantly with increasing oxygen partial pressure. This can be seen most clearly in the $40 \mathrm{~W}$ sample set. This can also be seen in the $20 \mathrm{~W}$ indium samples, though the two samples after the $1.20 \%$ oxygen volume fraction sample were omitted due to their resistivity values being much larger than the others, at $3300 \mathrm{ohm}$-square for the $1.60 \%$ and $>1 \mathrm{M} \Omega / \square$ for $2.00 \%$ oxygen volume fraction samples. Bulk resistivity values on the order of $10^{-4} \Omega$-cm were obtained with $40 \mathrm{~W} 2.80 \%$ and $60 \mathrm{~W} 4.00 \%$ indium, and nearly obtained with $20 \mathrm{~W} 1.20 \%$. 
Fig. 6 shows mobility with respect to oxygen volume fraction and indium deposition power. Low mobility is seen for $20 \mathrm{~W}$ indium in the non-transparent samples. As the film transitions to a transparent conducting oxide film, the mobility sharply increases until the film becomes over-saturated with oxygen and the mobility decreases. The trend is similar with $40 \mathrm{~W}$ and $60 \mathrm{~W}$ samples, which exhibit low mobility in the nontransparent region but have increases in mobility in the optimal levels. The decrease in mobility due to over-saturation of oxygen is not seen in the $40 \mathrm{~W}$ and $60 \mathrm{~W}$ samples, but is expected to occur if the oxygen volume fraction is increased to the over-saturation levels seen in the $20 \mathrm{~W}$ samples. The highest mobility observed in this study was the $4 \%$ oxygen volume fraction in the $60 \mathrm{~W}$ set.

Fig. 7 shows the carrier concentration of electrons in the film for a given oxygen volume fraction at each indium deposition power. The trend here is as anticipated: that the carrier concentration will drop as oxygen volume content increases. As oxygen content increases, oxygen vacancies which were previously donating electrons to the system are being filled. For each increase in indium power, there is an increase in carrier concentration, which also can be supported by carriers coming from interstation metal ion impurities or doping ions. Although having a higher carrier concentration will result in films with better resistivity values, an increase in carrier concentration can also contribute to reductions in transmission, particularly in the near-infrared.

\subsection{Ellipsometry analysis and results}

All ellipsometry data were analyzed with the Tauc-Lorentz Model. The results are summarized in Table 1. 
From Table 1, it can be seen that the thickness measurements obtained with both thin film measurement techniques are consistent. Furthermore, the roughness information, which is related to the deposited film quality, can also be obtained with the spectroscopic ellipsometry technique and is reported in the table.

Several modeled parameters are given in Table 2. With the Tauc-Lorentz dispersion, optical band gap could be readily obtained with a small uncertainty related to the three sigma output at $95 \%$ confidence from the mathematical regression. The band gap information is essential in optimizing film design and in evaluation of the film's performance. Samples $20 \mathrm{~W} 1.20 \%$, $40 \mathrm{~W} 2.80 \%$, and $60 \mathrm{~W} 4.00 \%$ had the best performance electrically and are shown to have a band-gap of $2.7-2.8 \mathrm{eV}$ from the Tauc-Lorentz method. Optical transmission measurements confirmed the criteria for optimization of both processing parameters and composition design. For comparison, the band-gaps from the Tauc plots (Fig. 3) are included in the table. It can be seen that typically the Tauc plots yield higher band-gaps than the Tauc-Lorentz method. Possibly, because the Tauc-Lorentz parameters are calculated from ellipsometry data, they may be more sensitive to phase information, unlike Tauc plots, which are generally used for estimated band-gap and are fit from from the transmission data. They both exhibit the same trends as discussed previously, with decreasing band-gap with increasing oxygen content in the films.

Optical constants, refractive index $(\mathrm{N})$, and extinction coefficient $(\mathrm{K})$, were plotted in Fig. 8 and Fig. 9 for the selected samples. Fig. 8 shows that the transparent samples all exhibit a similar refractive index in the visible region. Refractive index in the nearinfrared region is higher in samples with higher resistivity, with the highest refractive 
index observed for the $20 \mathrm{~W} 2.00 \%$ oxygen sample with resistivity on the order of $\mathrm{M} \Omega-\mathrm{cm}$. From Fig. 9, the K plot for these samples exhibits typical characteristics of TCO film, i.e. low absorption in the visible wavelength range. $\mathrm{N}$ and $\mathrm{K}$ values at the 400 , 633, 800, and $1500 \mathrm{~nm}$ wavelength are listed in Table 3 for comparison of each film obtained at different deposition conditions.

To examine the effects of the processing parameters on absorption behavior of the films, extinction coefficients $\mathrm{K}$ at a wavelength of $633 \mathrm{~nm}$ was plotted against the volume fraction of Oxygen at three different levels of sputtering power for indium. It can be seen that (1) absorption of films decreases with increasing oxygen concentration in the argonoxygen mixture at each sputtering power; (2) relatively higher oxygen concentration is needed to achieve smaller absorption at higher sputtering power.

\section{Discussion}

For solar cell applications where cost to performance is of major concern, the material and processing costs need to be balanced with the performance of the material. InZnO deposited in this study through a relatively simple room temperature deposition with no complicated steps has yielded electrical and optical transmittance which is on par with standard TCO materials such as ITO and AZO.

The films produced in this study use considerably less indium than typical ITO films, and were shown to have the ability to deposit with good electrical properties without annealing, on par with many reports on ITO $[18,19]$. They have been shown to have properties similar to AZO, although AZO currently remains a cheaper alternative [20,21]. In comparison to other TCOs, transmission is similar, though some of the samples 
exhibited transmission in the infra-red region that is greater than reported for ITO and AZO, which is beneficial for photovoltaic applications $[9,22]$. Future directions for this work include investigation of devices on CIGS in comparison with other TCO materials, and use with alternative CdS buffer developed in previous work [8].

\section{Conclusions}

InZnO films, deposited by magnetron co-sputtering at room temperature, were studied as a potential replacement material for typical TCO materials commonly used in research and commercial applications. The effects of the oxygen volume fraction in the flow gas on the electrical and optical properties of InZnO with no post deposition annealing were studied. InZnO can be deposited on par with other leading TCO materials with resistivity values as low as $\sim 5.5 \times 10^{-4}$ and optical transmission greater than $80 \%$ in the visible spectrum through oxygen optimization. Films with higher indium content were able to achieve high mobility values greater than $30 \mathrm{~cm}^{2} / \mathrm{V} \cdot \mathrm{S}$ with carrier concentrations low enough to maintain a high near-infrared transmission. The band-gap was found to be acceptable for photovoltaic applications ranging from 2.7-3.2 eV. Indium consumption compared to ITO have been considerably reduced without sacrificing film properties. In $\mathrm{ZnO}$ deposited under these conditions has thus demonstrated properties that are appropriate for use as the transparent conduction oxide for photovoltaic applications.

\section{Acknowledgement}


This work is partially funded by the United States Department of Energy (DOE) award number: DE-EE0004947. 


\section{References}

[1] H. Liu, V. Avrutin, N. Izyumskaya, Ü. Özgür, H. Morkoç, P. Int. Sch. Phys. 48 (2010) 458-484.

[2] A. Chandra, G. Anderson, S. Melkote, W. Gao, H. Haitjema, K. Wegener, CIRP Ann. Manuf. Techn. 63 (2014) 797-819.

[3] J. A. Stoke, J. D. Beach, W. C. Bradford, T. R. Ohno, Thin Solid Films 562 (2014) 254-259.

[4] K. Ellmer, Nat. Photonics 6 (2012) 809-817.

[5] T. Minami, Semicond. Sci. Tech. 20 (2005) S35-S44.

[6] M. Putri, C. Y. Koo, J. Lee, J. Kim, H. Y. Lee, Thin Solid Films 559 (2014) 44-48.

[7] P. Jackson, D. Hariskos, E. Lotter, S. Paetel, R. Wurz, R. Menner, W. Wischmann, M. Powalla, Prog. Photovolt. Res. Appl. 19 (2011) 894-897.

[8] J. N. Alexander, S. Higashiya, D. Caskey Jr, H. Efstathiadis, P. Haldar, Sol. Energ. Mat. Sol. Cells 125 (2014) 47-53.

[9] G. Gonçalves, E. Elangovan, P. Barquinha, L. Pereira, R. Martins, E. Fortunato, Thin Solid Films 515 (2007) 8562-8566.

[10] S. Jeong, J. Park, B. Lee, J. Alloys Compd. 617 (2014) 180-184.

[11] S. Park, J. Koh, Ceram. Int. 40 (2014) 10021-10025.

[12] J. D. Perkins, T. Gennett, J. E.Leisch, R. Sundaramoorthy, I. L. Repins, M. F. A. M. Van Hest, D. S. Ginley, $35^{\text {th }}$ IEEE PVSC (2010) 989-991.

[13] N. Naghavi, L. Dupont, C. Marcel, C. Maugy, B. Laïk, A. Rougier, C. Guéry, J. M. Tarascon, Electrochim. Acta 46 (2001) 2007-2013.

[14] G. E. Jellison, F. A. Modine, Appl. Phys. Lett. 69 (1996) 371-374. 
[15] H. G. Thompkins, E. A. Irene, Handbook of Ellipsometry, Norwich, New York, William Andrew, Inc., 2005.

[16] R. Hummel, Electronics Properties of Materials, third ed., New York, SpringerVerlag Berlin Heidelberg, 2000.

[17] W. Press, S. Teukolsky, W. Vetterling, B. Flannery, Numerical Recipes in C: The Art of Scientific Computing, second ed., Cambridge: Press Syndicate of the University of Cambridge, 1992.

[18] J. Hotovy, J. Hüpkes, W. Böttler, E. Marins, L. Spiess, T. Kups, V. Smirnov, I. Hotovy, J. Kováč, Appl. Surf. Sci. 269 (2013) 81-87.

[19] T. Koida, H. Fujiwara, M. Kondo, J. Non-Cryst. Solids 354 (2008) 2805-2808.

[20] T. Ghosh, D. Basak, Sol. Energy 96 (2013) 152-158.

[21] Q. Shi, K. Zhou, M. Dai, H. Hou, S. Lin, C. Wei, F. Hu, Ceram. Int. 39 (2013) 11351141.

[22] K. M. Yu, M. A. Mayer, D. T. Speaks, H. He, R. Zhao, L. Hsu, S. S. Mao, E. E. Haller, W. Walukiewicz, J. Appl. Phys. 111 (2012) 123505-123505-5. 


\section{List of Tables and Figures}

Table 1: Summary of all samples analyzed with Ellipsometry. Thickness and roughness from ellispometry is shown and compared with the values obtained through profilometry. Blank cells were samples that were not optically transparent.

Table 2: Summary of transparent samples modeled with the Tauc-Lorentz dispersion. A summary of the parameters is shown, along with a comparison of band-gap compared between the Tauc-Lorentz and Tauc Plot (Fig. 3).

Table 3: Summary of Optical constants $\mathrm{N}$ and $\mathrm{K}$ for all samples at 400, 633, 800, and $1500 \mathrm{~nm}$.

Fig. 1: Elemental composition of deposited films. For each power of indium, indium (blue), zinc (Orange), and oxygen (grey) are shown for each sample for a given oxygen volume fraction. Opaque and transparent samples are denoted by triangles and circles respectively.

Fig. 2: Growth rate for each sample is shown with respect to its deposition power and oxygen volume fraction. Opaque and transparent samples are denoted by triangles and circles respectively.

Fig. 3: Optical transmission from 250-1700 nm of InZnO/SLG for each sample.

Fig. 4: Tauc plots of the transmission data from Fig. 3. Summary of band-gaps shown in Table 2 with comparison to the Tauc-Lorentz model.

Fig. 5: Sheet resistance (top) and Bulk resistivity (bottom) as a function of oxygen volume fraction and indium power. $20 \mathrm{~W}, 40 \mathrm{~W}$, and $60 \mathrm{~W}$ is represented by blue, orange, and grey, respectively. Opaque and transparent samples are denoted by triangles and circles, respectively. 
Fig. 6: Mobility as a function of oxygen volume fraction and indium power. $20 \mathrm{~W}, 40 \mathrm{~W}$, and $60 \mathrm{~W}$ are represented by blue, orange, and grey, respectively. Opaque and transparent samples are denoted by triangles and circles, respectively.

Fig. 7: Bulk Carrier concentration as a function of oxygen volume fraction and indium power. $20 \mathrm{~W}, 40 \mathrm{~W}$, and $60 \mathrm{~W}$ are represented by blue, orange, and grey, respectively. Opaque and transparent samples are denoted by triangles and circles, respectively. Fig. 8: Optical constant $\mathrm{N}$ versus wavelength from $250-1700 \mathrm{~nm}$ for optically transparent samples.

Fig. 9: Optical constant K versus wavelength from 250 - $1700 \mathrm{~nm}$ for optically transparent samples.

Fig. 10: Extinction Coefficient $\mathrm{K}$ at $633 \mathrm{~nm}$ for all samples. Each indium deposition power is represented by a separate line. 
Table 1.

\begin{tabular}{ccccccc}
\hline $\begin{array}{c}\text { Sample Information } \\
\text { (Indium power, } \\
\text { Oxygen \%) }\end{array}$ & $\begin{array}{c}\text { Roughness } \\
(\mathrm{nm})\end{array}$ & Uncertainty & $\begin{array}{c}\text { Thickness } \\
(\mathrm{nm})\end{array}$ & Uncertainty & $\begin{array}{c}\text { Total Thickness } \\
(\mathrm{nm})\end{array}$ & $\begin{array}{c}\text { Film Thickness } \\
\text { from Profilometer } \\
(\mathrm{nm})\end{array}$ \\
\hline $20 \mathrm{~W}, 0.00 \%$ & - & - & - & - & - & 335 \\
$20 \mathrm{~W}, 0.40 \%$ & - & - & - & - & - & 305 \\
$20 \mathrm{~W}, 0.80 \%$ & - & - & - & - & 330 \\
$20 \mathrm{~W}, 1.20 \%$ & 5.95 & \pm 0.90 & 294.13 & \pm 2.05 & 300.08 & 290 \\
$20 \mathrm{~W}, 1.60 \%$ & 8.95 & \pm 1.10 & 253.86 & \pm 1.64 & 262.82 & 250 \\
$20 \mathrm{~W}, 2.00 \%$ & 9.14 & \pm 1.29 & 209.15 & \pm 1.64 & 218.29 & 230 \\
$40 \mathrm{~W}, 0.80 \%$ & - & - & - & - & - & 420 \\
$40 \mathrm{~W}, 1.60 \%$ & - & - & - & - & - & 440 \\
$40 \mathrm{~W}, 2.40 \%$ & - & - & - & - & 345.40 & 370 \\
$40 \mathrm{~W}, 2.40 \% *$ & 6.53 & \pm 0.95 & 338.87 & \pm 1.21 & 368.11 & 330 \\
$40 \mathrm{~W}, 2.80 \%$ & 6.23 & \pm 1.47 & 361.89 & \pm 2.36 & 338.03 & 290 \\
$40 \mathrm{~W}, 3.20 \%$ & 10.08 & \pm 0.81 & 327.96 & \pm 1.44 & - & 440 \\
$60 \mathrm{~W}, 3.20 \%$ & - & - & - & & - & 430 \\
$60 \mathrm{~W}, 3.60 \%$ & 9.21 & \pm 1.20 & 411.55 & \pm 2.84 & 418 & 4.09 \\
$60 \mathrm{~W}, 3.63 \% *$ & 6.61 & \pm 1.04 & 411.49 & \pm 2.39 & 418.09 & 420 \\
$60 \mathrm{~W}, 4.00 \%$ & 5.51 & \pm 1.17 & 425.45 & \pm 2.75 & 430.96 & 440 \\
\hline
\end{tabular}


Table 2.

\begin{tabular}{cccccccc}
\hline $\begin{array}{c}\text { Sample Information } \\
\text { (Indium power, }\end{array}$ & \multicolumn{1}{c}{} & & & & & \\
Oxygen \%) & $\mathrm{A}$ & $\mathrm{C}$ & $\mathrm{E}_{0}(\mathrm{eV})$ & $\mathrm{E}_{\mathrm{g}}(\mathrm{eV})$ & Uncertainty & $\mathrm{E}_{\infty}$ & $\mathrm{Eg}(\mathrm{eV})(\mathrm{Fig} .3)$ \\
\hline $20 \mathrm{~W}, 1.20 \%$ & 537.06 & 1.3098 & 2.6211 & 2.7987 & \pm 0.0178 & 2.0168 & 3.0 \\
$20 \mathrm{~W}, 1.60 \%$ & 520.76 & 1.3291 & 2.6581 & 2.7064 & \pm 0.0284 & 2.2048 & 2.8 \\
$20 \mathrm{~W}, 2.00 \%$ & 560.19 & 1.0857 & 2.1210 & 2.6807 & \pm 0.0362 & 2.6393 & 2.7 \\
$40 \mathrm{~W}, 2.40 \% *$ & 168.86 & 2.4440 & 4.8748 & 2.6288 & \pm 0.0280 & 2.3969 & 2.9 \\
$40 \mathrm{~W}, 2.80 \%$ & 153.90 & 4.5723 & 9.1444 & 2.6979 & \pm 0.0537 & 1.0664 & 3.0 \\
$40 \mathrm{~W}, 3.20 \%$ & 148.31 & 4.6316 & 9.2630 & 2.6113 & \pm 0.0326 & 1.1839 & 2.8 \\
$60 \mathrm{~W}, 3.60 \%$ & 237.14 & 5.4062 & 11.3455 & 3.1214 & \pm 0.1495 & 3.3896 & 3.2 \\
$60 \mathrm{~W}, 3.63 \% *$ & 182.12 & 2.4242 & 4.9055 & 2.9128 & \pm 0.0491 & 3.3165 & 3.2 \\
$60 \mathrm{~W}, 4.00 \%$ & 125.77 & 2.4404 & 4.9891 & 2.6629 & \pm 0.0264 & 4.1219 & 3.0 \\
\hline
\end{tabular}


Table 3.

\begin{tabular}{|c|c|c|c|c|c|c|c|c|}
\hline \multirow{3}{*}{$\begin{array}{l}\text { Sample Information } \\
\text { (Indium power, } \\
\text { Oxygen \%) }\end{array}$} & \multicolumn{8}{|c|}{ Optical Constant } \\
\hline & \multicolumn{2}{|c|}{$400 \mathrm{~nm}$} & \multicolumn{2}{|c|}{$633 \mathrm{~nm}$} & \multicolumn{2}{|c|}{$800 \mathrm{~nm}$} & \multicolumn{2}{|c|}{$1500 \mathrm{~nm}$} \\
\hline & $\mathrm{N}$ & $\mathrm{K}$ & $\mathrm{N}$ & $\mathrm{K}$ & $\mathrm{N}$ & $\mathrm{K}$ & $\mathrm{N}$ & $\mathrm{K}$ \\
\hline $20 \mathrm{~W} 0.00 \%$ & 1.8919 & 1.2891 & 2.3916 & 1.4786 & 2.6443 & 1.4157 & 2.6216 & 2.4959 \\
\hline $20 \mathrm{~W} 0.40 \%$ & 1.6876 & 0.8096 & 1.8929 & 0.9872 & 2.0834 & 0.9937 & 1.9206 & 1.7137 \\
\hline $20 \mathrm{~W} \quad 0.80 \%$ & 2.0682 & 0.2328 & 1.9901 & 0.1429 & 1.9541 & 0.1688 & 1.3354 & 0.9961 \\
\hline $20 \mathrm{~W} \quad 1.20 \%$ & 2.3042 & 0.1164 & 2.0538 & 0.0523 & 1.9623 & 0.0782 & 1.3405 & 0.5263 \\
\hline $20 \mathrm{~W} 1.60 \%$ & 2.3314 & 0.1826 & 2.098 & 0.0528 & 2.0399 & 0.0555 & 1.7011 & 0.8305 \\
\hline $20 \mathrm{~W} 2.00 \%$ & 2.2977 & 0.1312 & 2.0928 & 0.0074 & 2.0046 & 0.0130 & 1.7190 & 0.9210 \\
\hline $40 \mathrm{~W} \quad 0.80 \%$ & 2.3719 & 2.0528 & 3.2475 & 2.0299 & 3.5030 & 1.8308 & 3.4698 & 3.3364 \\
\hline $40 \mathrm{~W} 1.60 \%$ & 2.2728 & 0.8340 & 2.3896 & 0.9225 & 2.5217 & 0.8652 & 2.4000 & 1.7583 \\
\hline $40 \mathrm{~W} 2.40 \%$ & 2.2669 & 0.0859 & 2.0503 & 0.0328 & 1.9863 & 0.0833 & 1.1369 & 0.3238 \\
\hline $40 \mathrm{~W} 2.40 \% *$ & 2.3404 & 0.1146 & 2.0852 & 0.0036 & 2.0844 & 0.0780 & 1.3695 & 0.7408 \\
\hline $40 \mathrm{~W} 2.80 \%$ & 2.3505 & 0.0898 & 2.0988 & 0.0260 & 2.0578 & 0.0924 & 1.2300 & 0.3341 \\
\hline $40 \mathrm{~W} 3.20 \%$ & 2.3263 & 0.0962 & 2.0906 & 0.0167 & 2.1188 & 0.1048 & 1.4695 & 0.7283 \\
\hline $60 \mathrm{~W} 3.20 \%$ & 2.1991 & 0.2860 & 2.2112 & 0.2895 & 2.1250 & 0.2453 & 3.5124 & 0.0133 \\
\hline $60 \mathrm{~W} 3.60 \%$ & 2.2553 & 0.0740 & 2.0271 & 0.0402 & 1.9574 & 0.0407 & 1.0681 & 0.3284 \\
\hline $60 \mathrm{~W} 3.63 \% *$ & 2.2766 & 0.0640 & 2.0345 & 0.0281 & 1.9538 & 0.0304 & 1.0192 & 0.3205 \\
\hline $60 \mathrm{~W} 4.00 \%$ & 2.3157 & 0.0908 & 2.0679 & 0.0307 & 2.0417 & 0.0813 & 1.2775 & 0.3762 \\
\hline
\end{tabular}




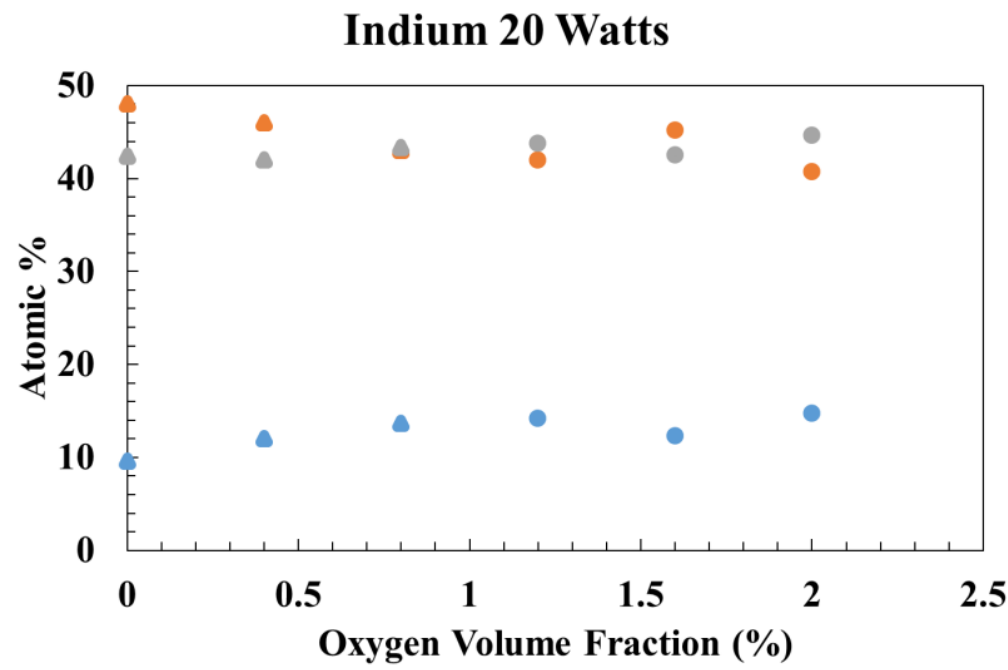

- Indium Content $\triangle$ Zinc Content $\triangle$ Oxygen Content Indium 60 Watts

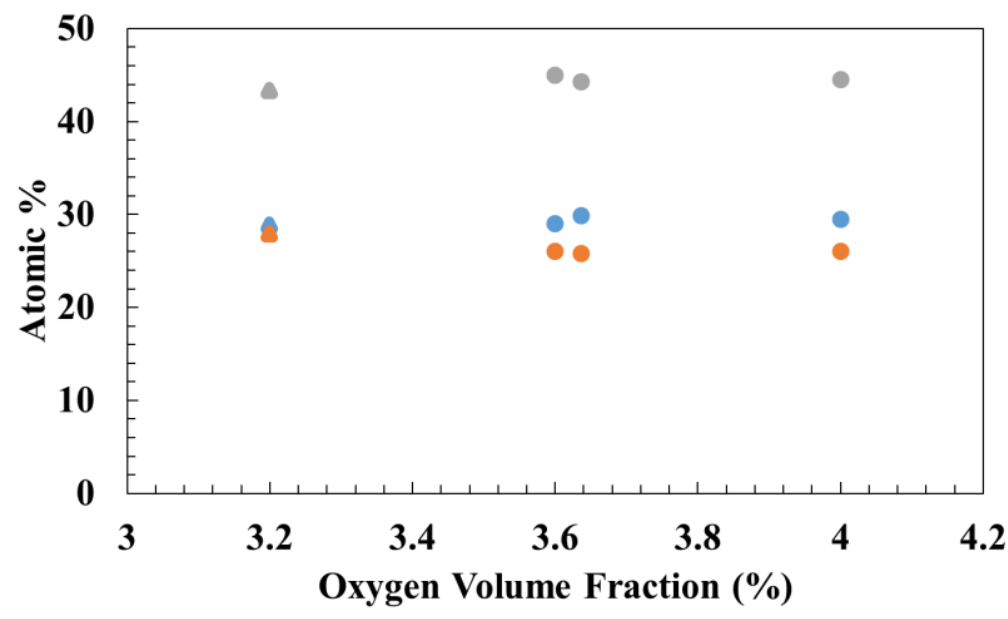

- Indium Content • Zinc Content • Oxygen Content
Indium 40 Watts

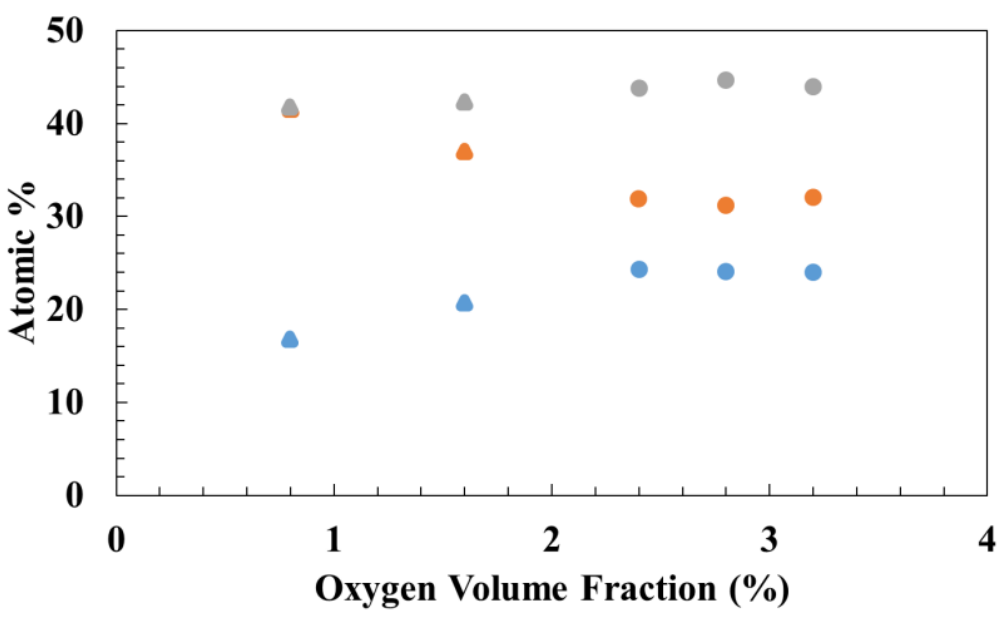

- Indium Content $\bullet$ Zinc Content $\bullet$ Oxygen Content Best Performing Samples

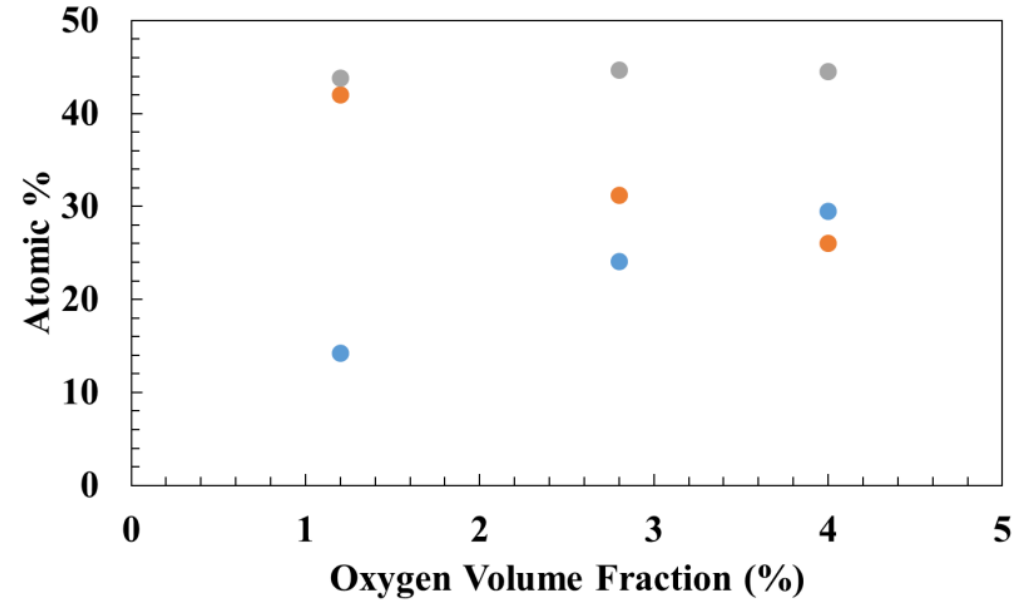

- Indium Content • Zinc Content • Oxygen Content 


\section{Growth Rate}

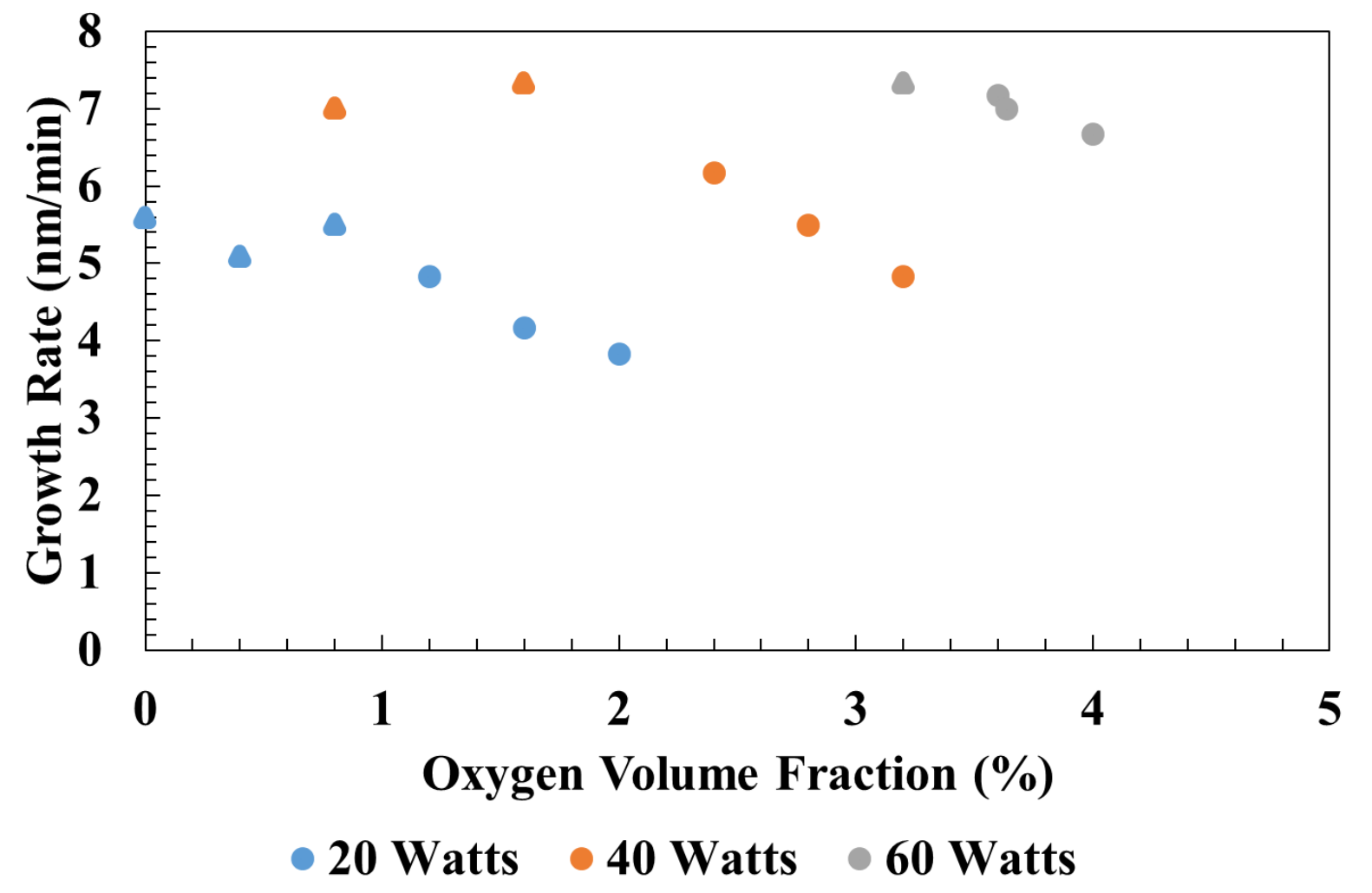




\section{Figure 3}
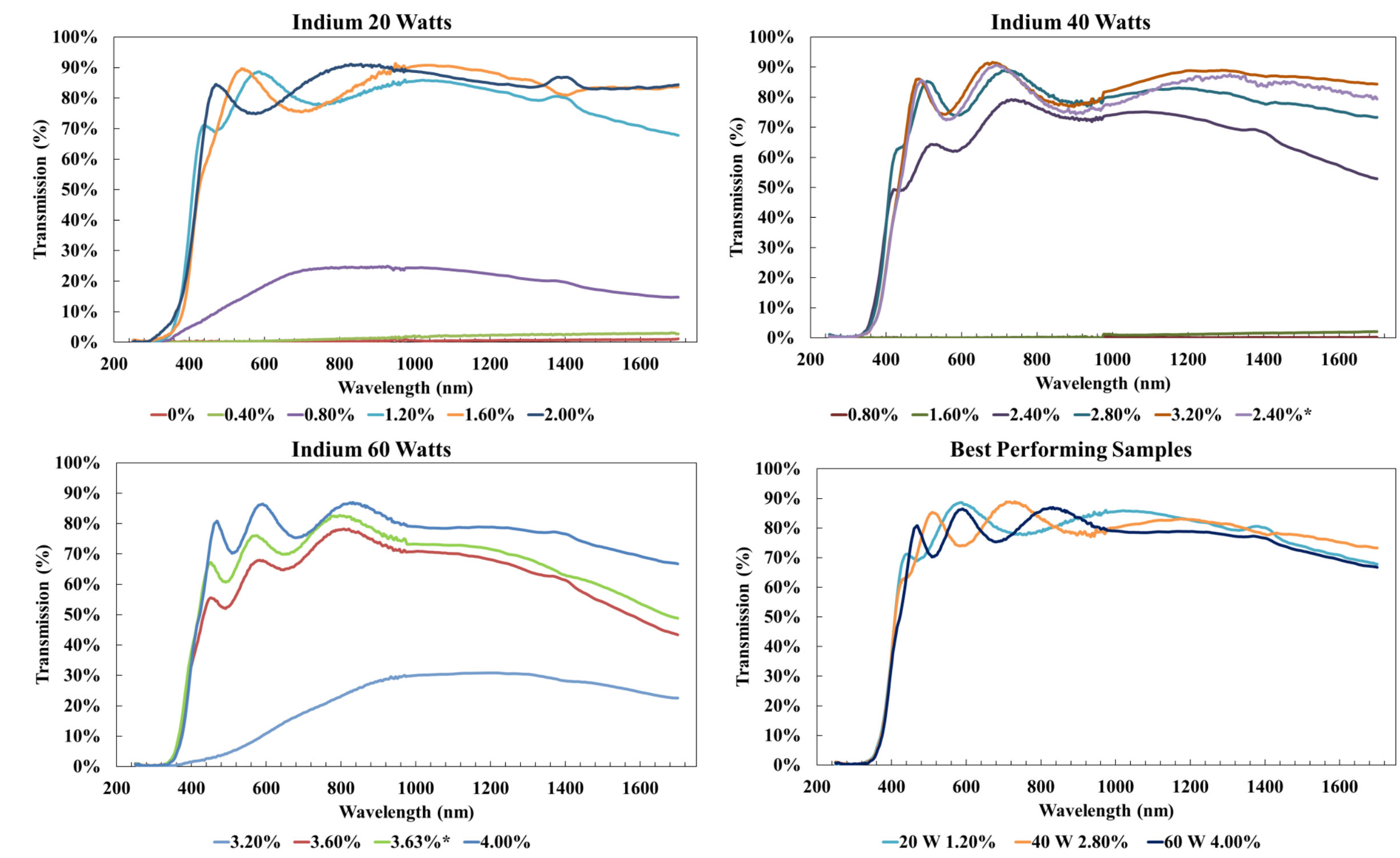

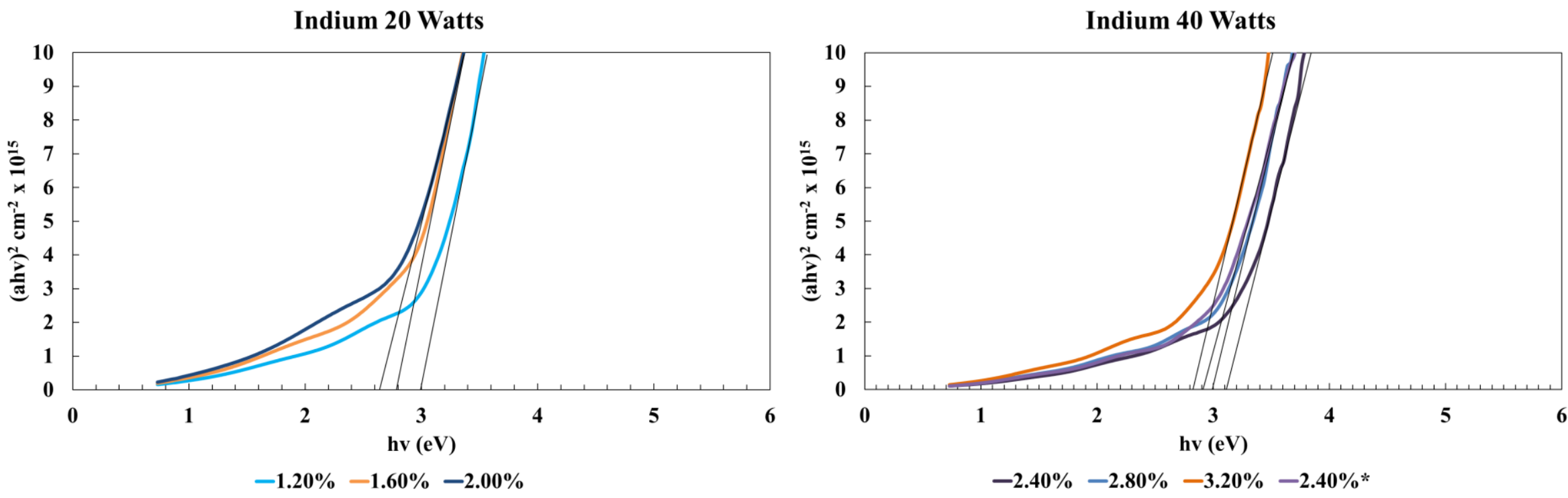

Indium 60 Watts

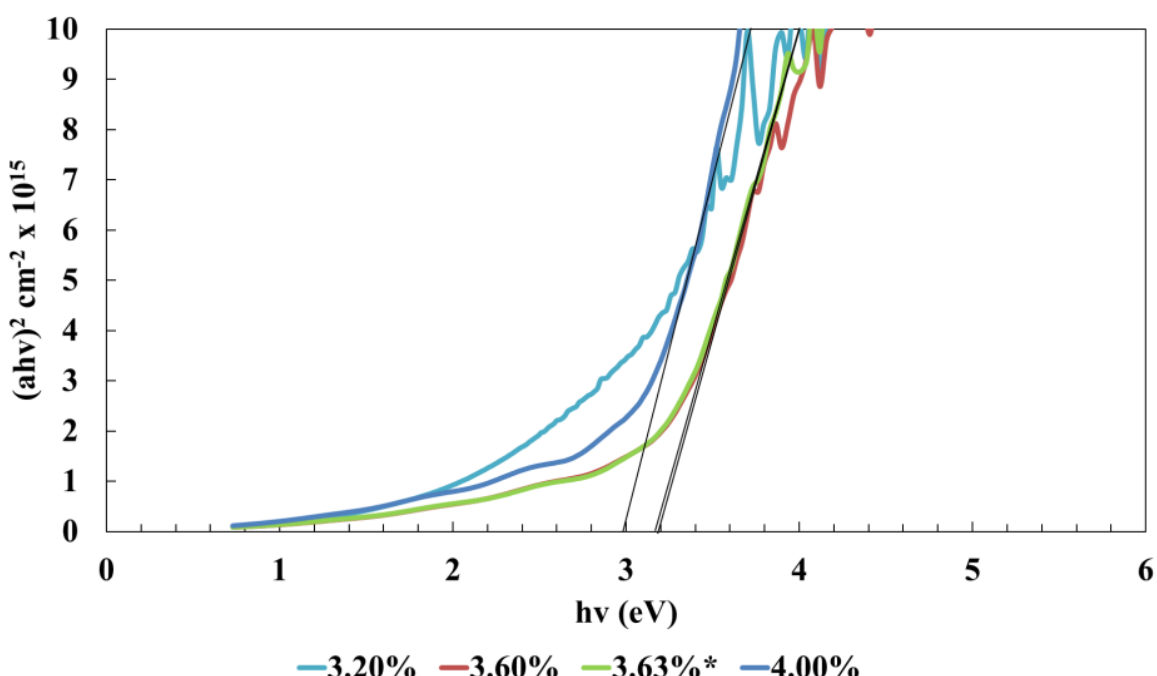

Best Performing Samples

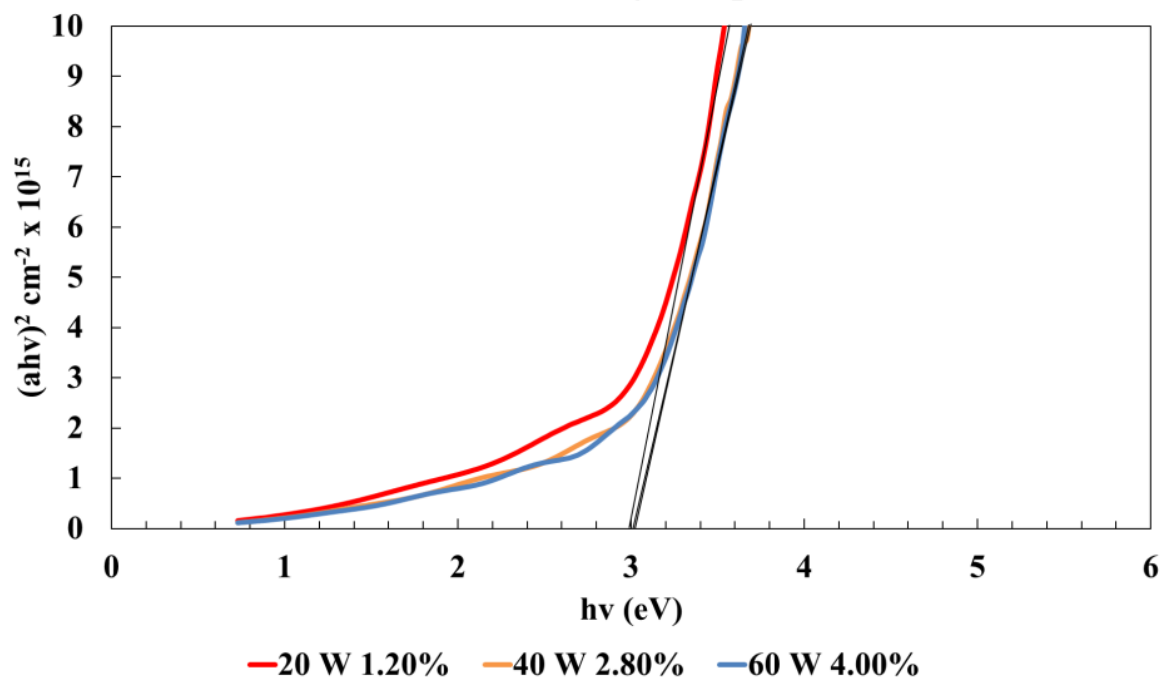



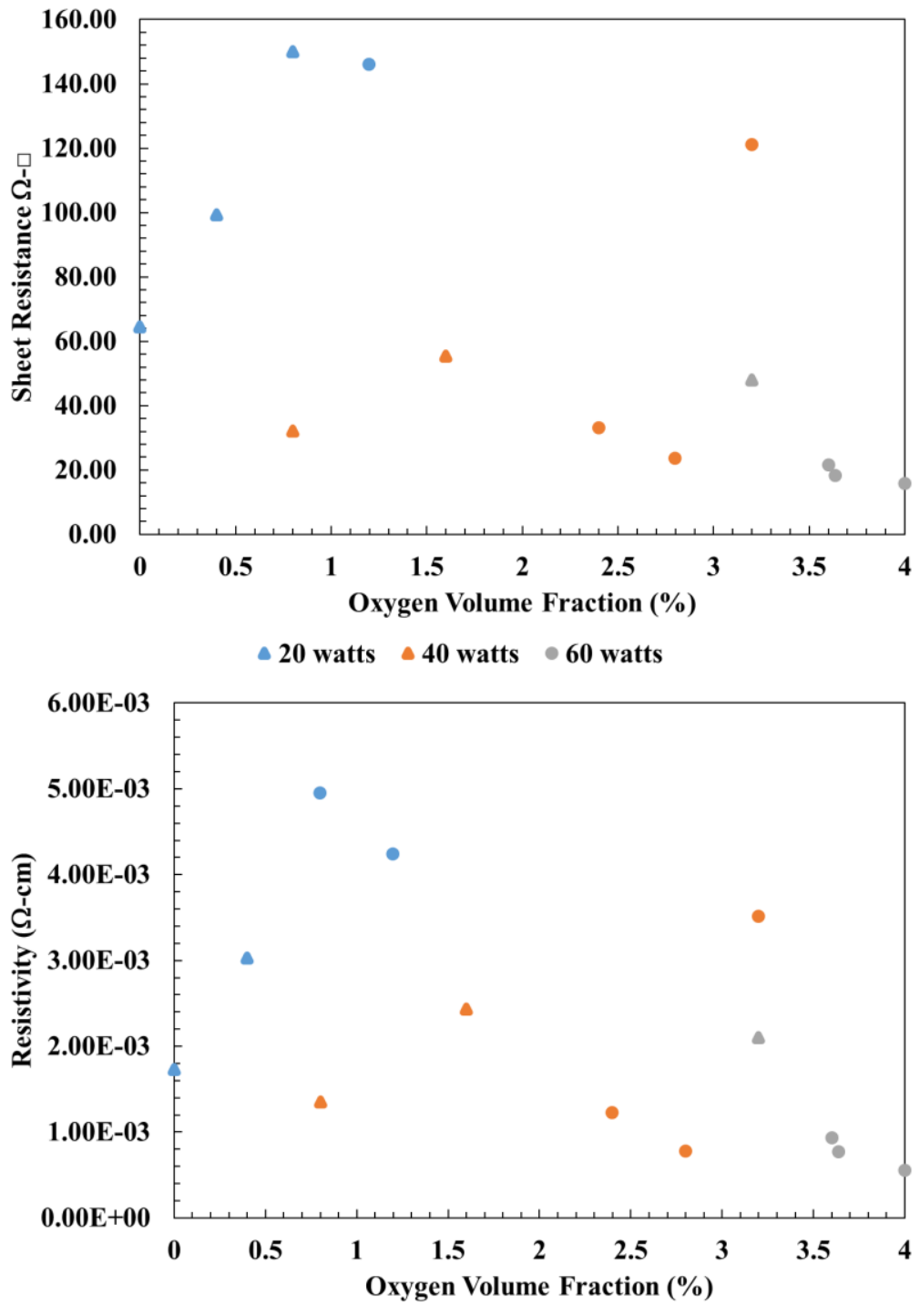

$\triangle 20$ watts $\triangle 40$ watts $\bullet 60$ watts 


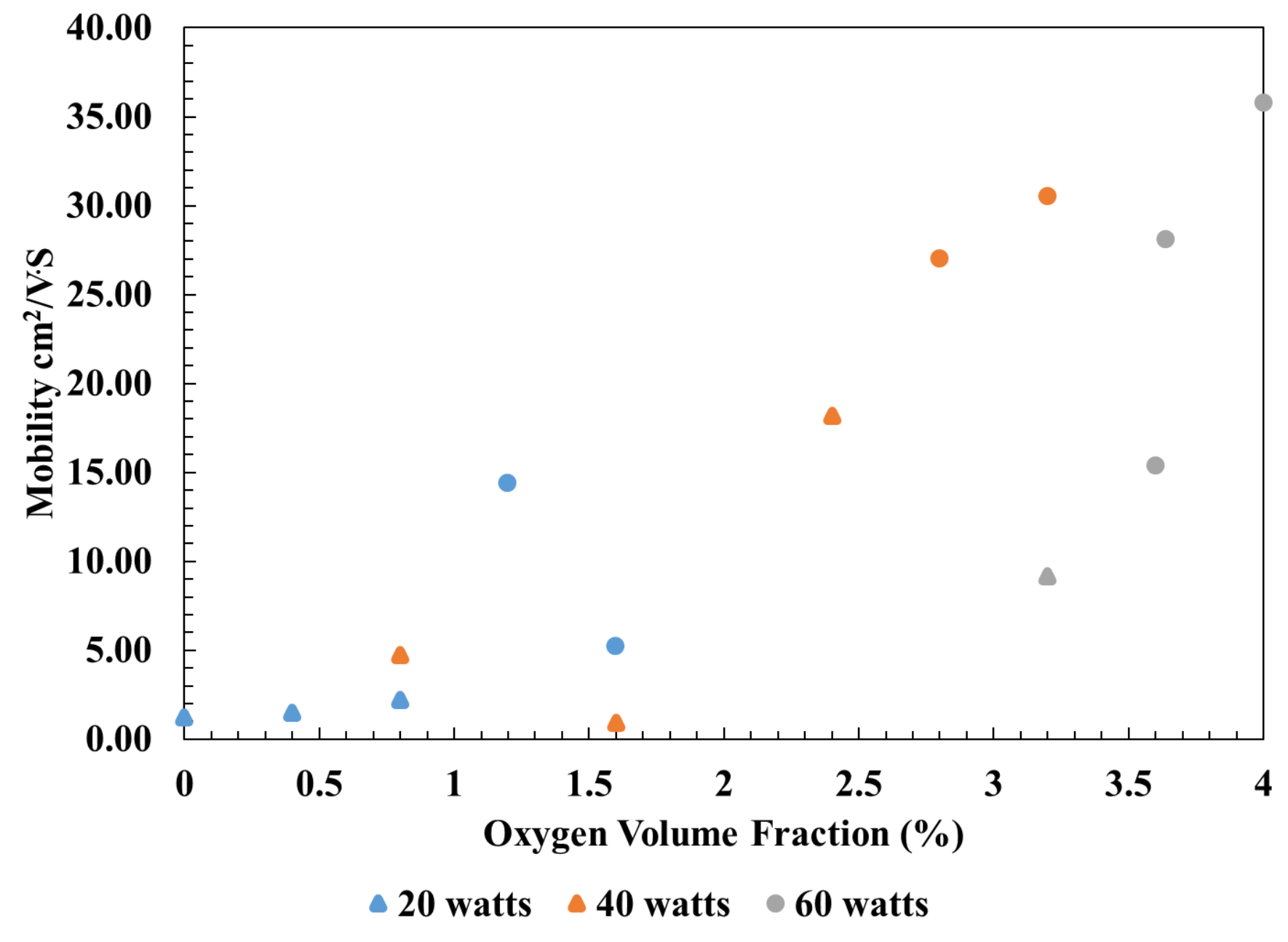




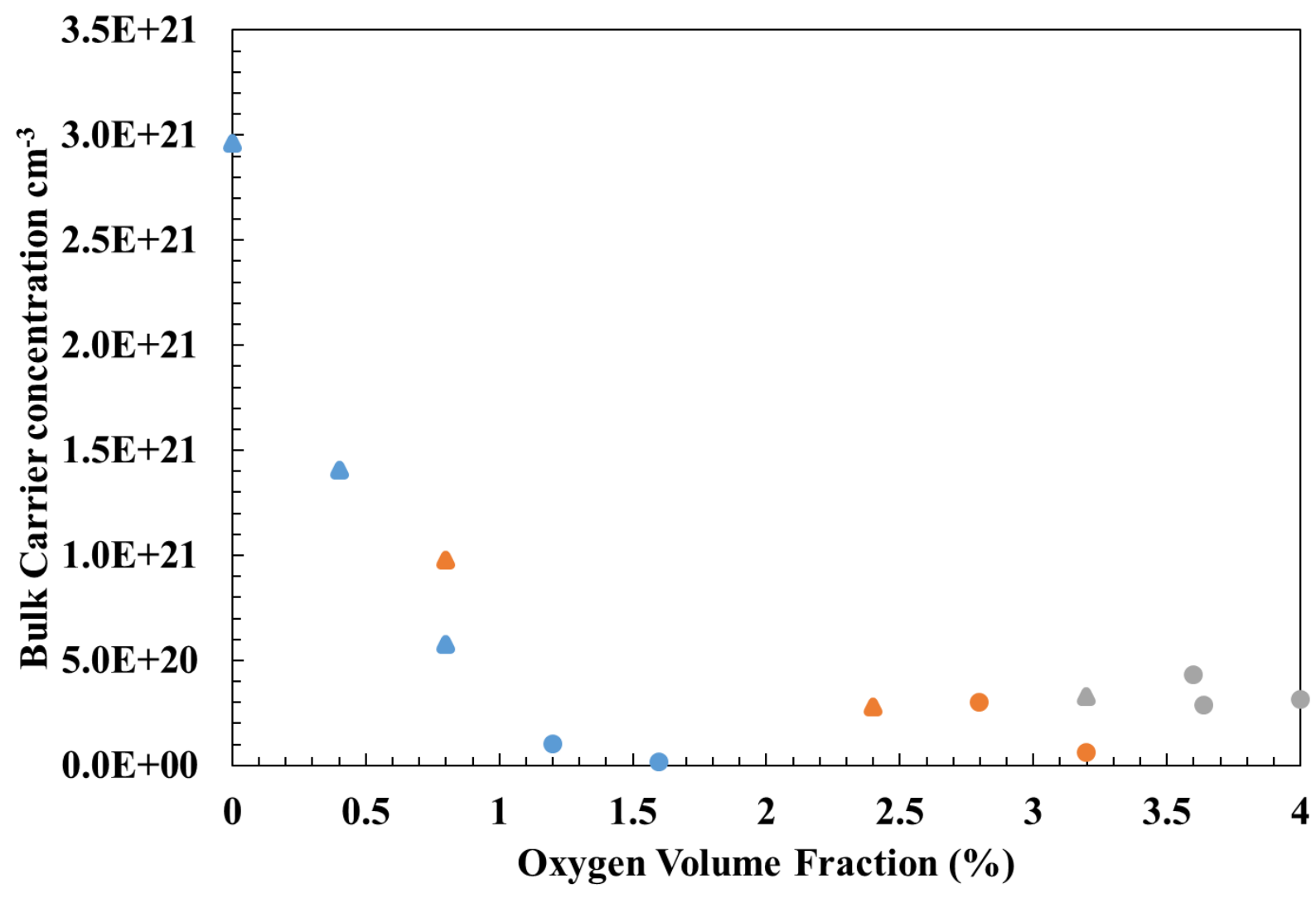

$\triangle 20$ watts $\triangle 40$ watts $\bullet 60$ watts 


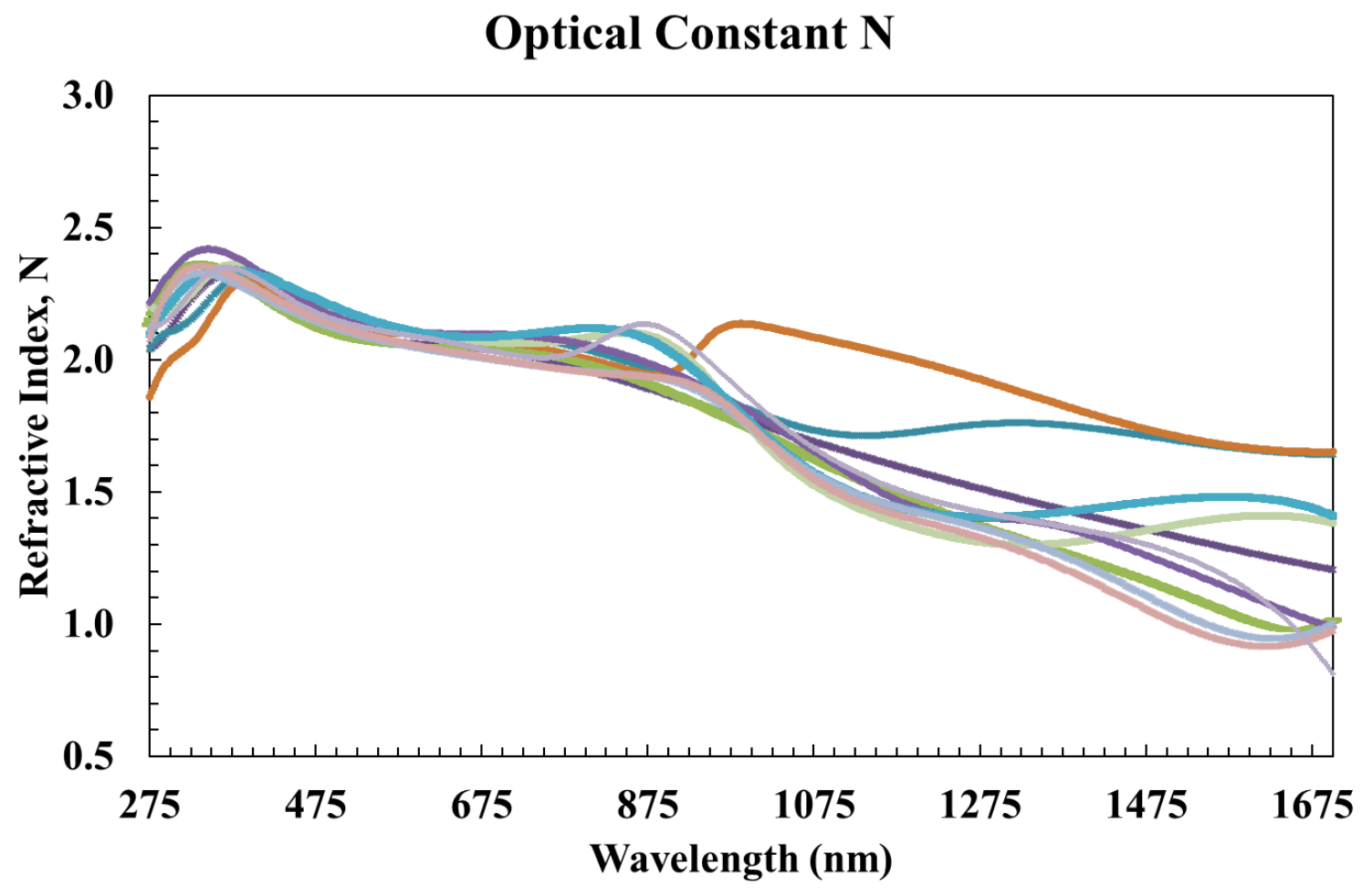

$-20 \mathrm{~W} 1.20 \%-20 \mathrm{~W} 1.60 \%-20 \mathrm{~W} 2.00 \%-40 \mathrm{~W} 2.40 \%-40 \mathrm{~W} 2.40 \%$ *

$-40 \mathrm{~W} 2.80 \%-40 \mathrm{~W} 3.20 \%-60 \mathrm{~W} 3.60 \%-60 \mathrm{~W} 3.63 \% *-60 \mathrm{~W} 4.00 \%$ 


\section{Optical Constant K}

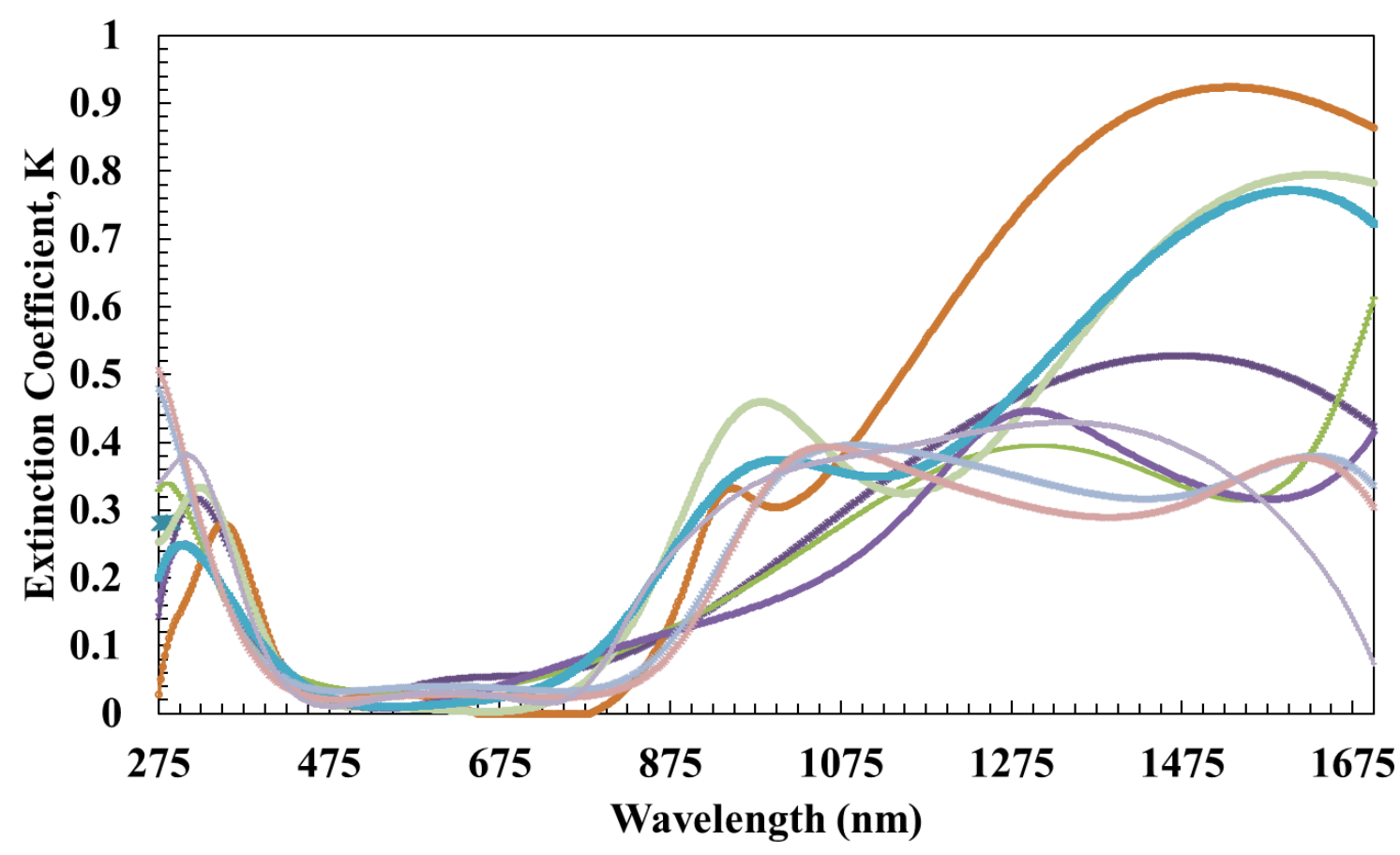

$-20 \mathrm{~W} 1.20 \%-20 \mathrm{~W} 1.60 \% \rightarrow-20 \mathrm{~W} 2.00 \%-40 \mathrm{~W} 2.40 \%-40 \mathrm{~W} 2.40 \% *$

$-40 \mathrm{~W} 2.80 \%-40 \mathrm{~W} 3.20 \%-60 \mathrm{~W} 3.60 \%-60 \mathrm{~W} 3.63 \% *-60 \mathrm{~W} 4.00 \%$ 


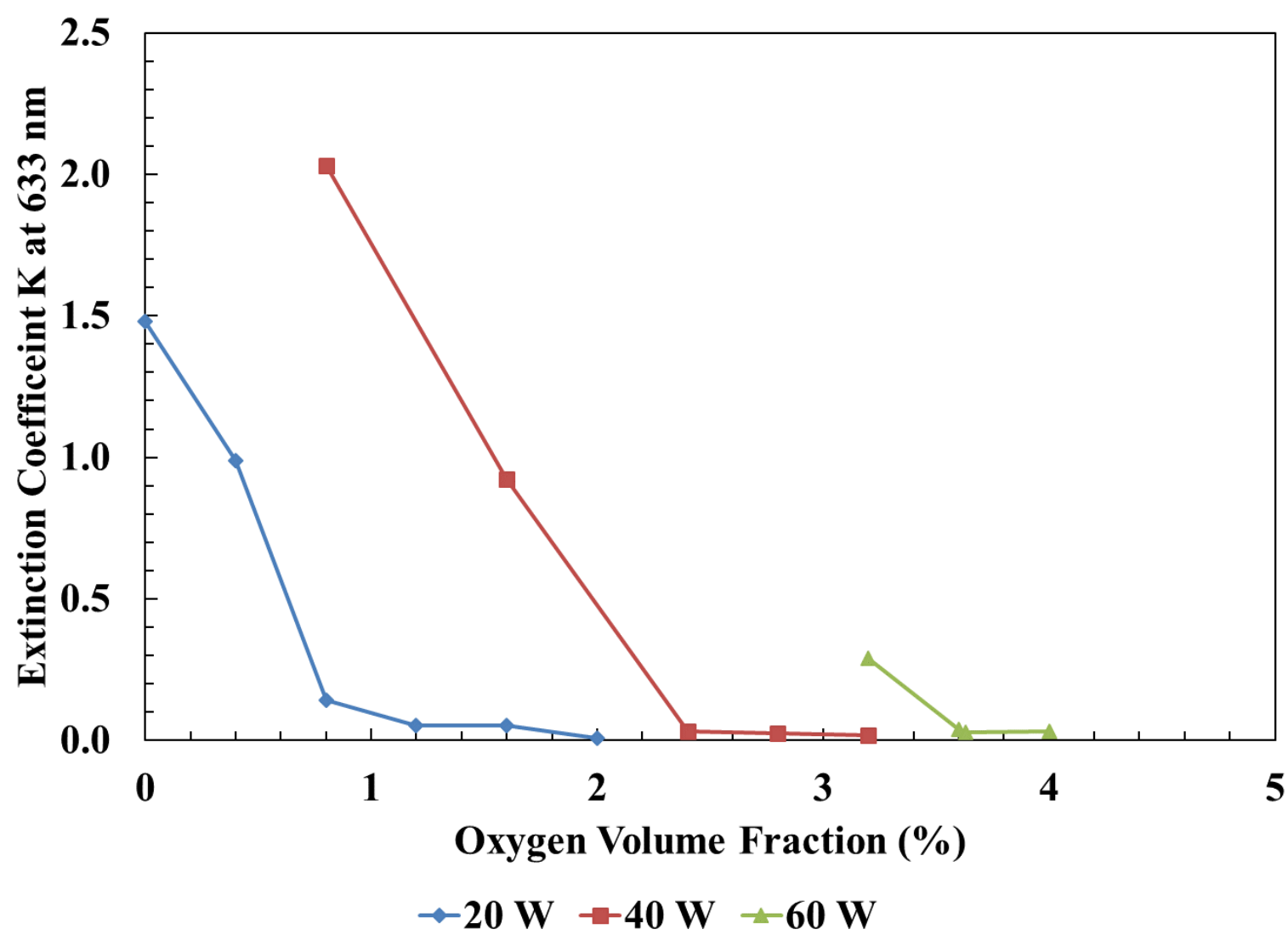

